\title{
Sob o primado da palavra: o universo feminino/feminista das mulheres d'A República dos sonhos, de Nélida Piñon
}

\author{
Lúcia Osana Zolin*
}

O romance A república dos sonhos (1984), de Nélida Piñon, ocupa um lugar à parte na história da literatura brasileira. Nas palavras da escritora, trata-se de sua "suma teológica. Conta a história desse país nos últimos cem anos, mas, mais do que isso, conta a história das utopias europeias em relação à Europa e também da utopia brasileira inventada por seus brasileiros" (Piñon, apud ProençA Filho, 1998, p. 4). Minha perspectiva de leitura, como pesquisadora que sou da literatura de autoria feminina brasileira, ilumina, nessas páginas em que o estético rende tributo ao político, sem medo de soar menos estético ou menos literário, a trajetória da emancipação da mulher.

Ao narrar a saga familiar do imigrante Madruga, desde a sua chegada no Brasil, no início do século, Nélida Piñon, num certo sentido, narra também, por meio das representações das mulheres que compõem a trama, a história da emancipação feminina (Zolın, 2003). Tal história, embora não seja explicitamente declarada, aparece diluída ao longo do romance, alicerçando e compondo as trajetórias das várias gerações de mulheres que se fizeram presentes na vida do protagonista: a avó, a mãe, a esposa, as filhas, as noras e a neta, além da agregada Odete.

Tais figuras femininas acabam por constituir um grande painel em que se pode vislumbrar, de um lado, as personagens principais representando os diversos estágios por que passou a mulher até atingir o grau de emancipação que a vemos desfrutar em meados dos anos 1980, o momento presente da narrativa; e, de outro, as personagens secundárias, ora preparando o ambiente em que florescerão as ações daquelas, ora lhes servindo de contraponto.

Trata-se de um elenco de figuras femininas marcadas pela pluralidade e/ou pela diferença identitária que desautoriza qualquer tentativa de lhes conferir unidade sob o rótulo de, simplesmente, "mulheres", no sentido tomado pelo estruturalismo, responsável pela divisão da humanidade em dois polos: o feminino e o masculino - consequentemente, homens $\mathrm{x}$ mulheres, dominantes $\mathrm{x}$ dominadas, opressores x oprimidas. Segundo Judith Butler, "se alguém 'é' uma mulher, isso certa-

Professora Associada de Teorias Linguísticas e Literárias da Universidade Estadual de Maringá. Maringá, Paraná, Brasil. E-mail: luciazolin@yahoo.com .br. 
mente não é tudo o que esse alguém é" (2003, p. 20). Já é consenso no âmbito do pensamento feminista o fato de não haver unidade na categoria mulheres. Tratase de uma categoria des-essencializada, ou seja, sem identidade fixa, sempre em processo, cuja evolução é afetada pelo entrecruzamento com outros eixos, além do gênero, como raça, classe, sexualidade, etnia, faixa etária etc.

Tendo tal constatação em vista, na nossa leitura de $A$ república dos sonhos, emerge claramente o fato de a ideologia que subjaz à sua construção ser permeada pelo pensamento feminista que, por volta de meados do século passado, se disseminou no mundo ocidental. Ao engendrar as representações das mulheres que constituem a família do protagonista Madruga, a escritora se afasta das imagens femininas estereotipadas que povoam, frequentemente, a literatura canônica e o imaginário coletivo derivado do pensamento patriarcal, para, em seu lugar, edificar outras, marcadas pela heterogeneidade das identidades femininas de inspiração mais realista.

No decorrer de suas 76o páginas, divididas em 36 partes, o/a leitor/a se depara com a história da família que imigra da Espanha para o Brasil no início do século $\mathrm{XX}$ amalgamada aos principais acontecimentos históricos dos dois países. A obra abarca eventos que vão desde a infância do protagonista Madruga, nascido em 1900 na Espanha, passando pela sua chegada no Brasil em 1913, sua ascensão como negociante e o destino de sua família 70 anos depois, em 1983; bem como densas reflexões político-culturais relacionadas às nações que servem de cenário à trama. Sobre o Brasil, os principais fatos políticos do século XX são intercalados com reflexões que remetem às raízes do autoritarismo e da escravidão que marcaram o século XIX. Acerca da Espanha, há considerações sobre a perda gradual da identidade cultural do povo galego e do povo cigano sob o domínio de Castela, e sobre a guerra civil espanhola, com a vitória da ditadura de Franco.

Do ponto de vista dessa intervenção, importa colocar luz no processo pelo qual a mulher se afasta da obscuridade, da resignação e, sobretudo, do silenciamento, a ela impostos pela cultura patriarcal. No grande painel de figuras femininas que constituem o romance de Piñon, figuram realidades femininas múltiplas e disformes que vão desde a campesina oitocentista, representante das mais tradicionais raízes galegas (Teodora - a avó paterna do protagonista); passando por sua contraparente, marcada pelo desejo de transcender a realidade disfórica do tempo, ainda que fosse por intermédio do filho (Urcesina - a mãe); depois, já no século XX, por uma mulher mais refinada, entretanto, mantida "protegida", pelo pai e pelo marido, dos perigos de viver, bem ao estilo patriarcal (Eulália - a esposa); a seguir, pela mais autêntica representante do inconformismo em relação ao modo de estar da mulher nessa sociedade, construída sobre os alicerces do patriarcalismo (Esperança, a filha mais velha); chegando, por fim, na mulher liberada dos anos 1980, capaz de se fazer respeitar, qualquer que seja a sua vontade (Breta, a neta).

Nesse grande painel de figuras femininas que compõem o romance, Eulália, Esperança e Breta são centrais. A análise da evolução de suas trajetórias, segundo 
uma ordem cronológica, levou-nos a reconhecer na ocasião em que defendemos nossa tese de doutorado, no conjunto, a mesma lógica que marcou a trajetória das conquistas sociais da mulher no século passado, viabilizadas pelo movimento feminista. ${ }^{1}$ Dito de outra forma, o modo como Eulália, Esperança e Breta foram construídas nos levou a fazer associações com o percurso histórico da mulher, galgado nos limites do século XX, rumo à sua emancipação, de acordo com o estado de coisas que se podia vislumbrar na década de 1980 no Brasil.

Se no caso de Eulália, o marido e o pai "haviam-lhe explicado a vida pela metade" (PIÑon, 1984, p. 14), segundo a cartilha da ideologia patriarcal, daí seu comportamento ser marcado mais pela resistência que pela ação face aos desmandos do patriarcalismo, sua filha mais velha, sugestivamente chamada Esperança, reagiu, lutando, literalmente, até a morte pelo direito de gerir a própria vida: o suicídio que coroa o final de sua longa trajetória de guerrilhas contra o sistema patriarcal não nos parece concebido como punição às suas transgressões, à moda dos desfechos tradicionais das heroínas oitocentistas; tampouco nos parece sinal de esgotamento por parte da personagem, sinalizando a situação-limite que a teria conduzido ao autoaniquilamento. Mas, sim, o coroamento da sua luta, em uma última e decisiva cartada, contra a teia de instituições e práticas sociais que o sistema de gênero envolve, como a divisão sexual do trabalho, a representação de papéis sexuais rígidos, a supervalorização do casamento e as limitações no que toca à expressão de escolhas, da sexualidade e do desejo femininos. E, ainda que sua morte aponte para uma espécie de enquadramento na Lei do Pai, tal hipótese é relativa porque, se a ela não foi permitido viver sua escolha com serenidade, já que a solidão, o abandono e a pressão social supostamente a conduziram à morte, ela pôde, por meio desse ato extremo, sinalizar a insustentabilidade dos cerceamentos empreendidos pelas práticas patriarcais às mulheres.

Em vista disso, podemos dizer que, em A república dos sonhos, Piñon toma o modelo feminino concebido ideologicamente pelo patriarcalismo como um parâmetro a partir do qual executa múltiplos deslocamentos semânticos, entendidos como lugares femininos de resistência. Na trajetória de Esperança, o parâmetro a partir do qual a escritora opera a maioria dos deslocamentos semânticos é o casamento, tomado como uma instituição legitimadora do exercício sexual e da procriação. A reflexão abaixo, de Schmidt (1999), contempla o significado desta instituição no universo romanesco, considerado de forma ampla:

Como aponta Leo Bersani, "na tradição do romance moderno, o casamento completa o sentido", mesmo quando não figure como uma resolução, seja feliz ou infeliz. Sua importância não é puramente formal, uma vez que imprime na narrativa uma estrutura significante que traduz um modo de produção de relações sociais altamente valorizadas e coerentes com a visão de um mundo capitalista e burguês, cujo discurso morali-

1 Ver Zolin (2003). 
zante está centrado no valor da domesticidade a partir da naturalização da mulher no espaço "sagrado" do lar (SchmidT, 1999, p. 673).

Este apontamento faz emergir a vastidão dos deslocamentos semânticos que o modo de construção de Esperança implica, em relação ao modelo de comportamento estabelecido pela ideologia patriarcal, corriqueiramente representado na literatura moderna. Ao relacionar-se afetivamente com um homem casado, engravidar dele, e após ser banida da casa paterna, ter a filha e viver com ela por sua conta e risco, Esperança contraria todas as expectativas do senso-comum em face das quais este modo de gerir a vida assume os foros do não-senso.

Mas é o percurso de Breta que nos interessa mais de perto nessas reflexões, em que nos empenhamos em iluminar a importância da conquista do direito à expressão como forma de subjetificação da mulher. Trata-se da terceira personagem que vem compor, junto com Eulália e Esperança, o trio de personagens femininas cujas trajetórias no conjunto, segundo nossa tese, remetem à trajetória da emancipação feminina, galgada no âmbito do feminismo.

Representando o avesso das tradicionais figuras femininas, enredadas no sistema de gênero, do qual a mulher sempre fora prisioneira, Breta configura-se como uma mulher liberada, com direito à voz e à vez no ambiente em que se insere. Sua postura sociocultural se configura a partir de constantes deslocamentos semânticos operados em relação aos valores embutidos nas relações de gênero e nos papeis tradicionalmente conferidos à mulher. Assim acontece no âmbito das relações amorosas, em que ela repudia o casamento como instituição altamente valorizada no mundo patriarcal, capitalista e burguês; no âmbito de suas crenças políticoideológicas, em que, no auge da ditadura militar, se compromete com grupos subversivos de esquerda, fazendo-se respeitar pelos que a cercam; no âmbito profissional, em que se faz escritora, profissão tradicionalmente masculina, imbuída do direito de narrar segundo uma ótica revisionista, crítica e racional; e acontece, principalmente, no âmbito familiar, no qual consegue introduzir pontos de vista diferentes daquele disseminado pela ideologia patriarcal, alicerce sobre o qual a família do avô fora estruturada.

Composto por meio de uma sofisticada teia de focos narrativos, o romance avança na medida mesma em que se alternam discursos e pontos de vista e, assim, maneiras diferentes de ver e equacionar a realidade circundante. E é nesse processo que o/a leitor/a vai tomando conhecimento da conquista de Breta do direito de narrar. Sendo a matéria do romance a saga vivenciada por Madruga ao imigrar para o Brasil ainda garoto para vir "fazer a América"; sendo, no âmbito de tal saga, Breta incumbida pelo avô de contar/escrever a sua história, sendo ela uma escritora; e, em se aceitando, como defendemos, a tese de que o romance comporta a história da emancipação feminina, por meio do modo como vão se desdobrando o modus vivendi das sucessivas gerações de mulheres que o compõem; é de Breta (alter ego da escritora?) a perspectiva organizacional de toda a trama. Isso implica 
dizer que o romance está alicerçado no princípio de que tanto as escolhas estéticas, quanto as ideológicas nele contidas, passam pelo crivo da mulher. É Breta a responsável pelas escolhas acerca da matéria narrada e, portanto, do que fazer lembrar ou do que fazer esquecer.

Considerando, conforme nos ensina Michael Pollak (1989), que é por meio do manejo da memória que os fatos sociais se tornam coisas, ou seja, passam a ser dotados de duração e estabilidade, há que se levar em conta o modo como a memória oficial ou, no caso que aqui mais de perto nos interessa, a memória da dominação masculina foi sendo solidificada; de outro lado, interessa igualmente colocar luz nas memórias das subversões desses paradigmas de opressão.

É tendo em vista esse processo que nos parece claro o fato de a escritora/narradora Breta escolher, no exercício de seu ofício e no cumprimento da missão recebida, iluminar a trajetória de cada uma das mulheres relacionadas à genealogia do avô, de modo a lhes salientar as práticas de opressão a que estiveram expostas, resultantes dos matizes patriarcais incidentes sobre as conjunturas socioculturais em que se inseriam. E, ao fazê-lo, trazer à tona o árduo caminho que à mulher foi necessário percorrer até o advento da libertação feminista e, com ela, a conquista do direito feminino de narrar/falar. Trata-se, é certo, de fixar um itinerário percorrido pela mulher, cujo retorno/retrocesso está fora de questão.

Em A república dos sonhos (1984), Nélida Piñon inaugura o que, talvez, pudéssemos chamar de tradição feminina/feminista de narradoras. Na literatura brasileira contemporânea de autoria feminina, publicada entre os anos 2000 e $2015,{ }^{2}$ não são raras as representações de narradoras-protagonistas que, em alguma medida, põem-se a escrever em uma espécie de estratégia, consciente ou casual, de subjetificação, reivindicando para si o direito de terem sua perspectiva considerada pelos que as cercam; ou mesmo, a oportunidade de compreenderem a si próprias e às suas angústias. Seja motivada pelos embates cotidianos das personagens femininas, seja por suas crises existenciais, ou por se encontrarem em situaçõeslimite, a prática da escrita sinaliza, em suas trajetórias, uma possibilidade de sal-

2 Consultar Zolin (2018a) e Zolin (2018b): resultados da pesquisa "Literatura de autoria feminina contemporânea: escolhas inclusivas?", desenvolvida sob minha coordenação na Universidade Estadual de Maringá, cujo principal objetivo foi mapear o modo de representação de personagens na literatura de mulheres brasileiras dada a público entre os anos 2000 e 2015, pelas editoras Companhia das Letras, Rocco e Record. Esses resultados revelam que tais romances [30\% do total de romances publicados no mesmo período por essas mesmas editoras] são predominantemente protagonizados por personagens femininas (65,3\%), em idade adulta/maturidade $(50,6 \%)$, letradas (53,1\% tem curso superior), vivenciando conflitos típicos da pós-modernidade, em que avultam questões identitárias $(28,4 \%)$, amalgamadas às implicações do espaço multifacetado dos grandes centros urbanos, em que se encontram inseridas $(82,7 \%)$, por onde frequentemente transitam sem se dar conta de que tais espaços eram, tradicionalmente, interditados à mulher; são igualmente representadas empreendendo constantes deslocamentos espaciais, em forma de viagens, mudanças, ou peregrinações (25,9\%); além disso, são imbuídas do direito de falar, caso das protagonistas que são também as narradoras de suas histórias (42\%) e de representar, caso das personagens-escritoras $(10,7 \%)$. 
vação, uma maneira de organizar o pensamento, fazer escolhas, responder ou buscar respostas para silenciamentos e outras interdições a que foram submetidas.

Trata-se de personagens cujas questões que as afetam são as mesmas que afetam o sujeito contemporâneo, marcado por descentramentos de ordem diversa, conforme explica Hall (2006), responsáveis pela fragmentação de suas identidades. Dentre tais descentramentos, o teórico ressalta o da linguagem, estudado por Ferdinand de Saussure, calcado no fato de a linguagem exorbitar a realidade, atualizando significados embutidos na língua que falamos e nos sistemas culturais em que nos inserimos. Nesse sentido, o real deixa de ser entendido como da ordem do ontológico, para ser considerado um efeito de linguagem. Trata-se da chamada virada linguística, que, nos anos 1970, marcou o desenvolvimento das diversas áreas da filosofia ocidental a partir dessa mudança de foco no modo de apreensão/compreensão da realidade.

Tal constatação resultou, por exemplo, em estudos realizados no campo da comunicação que, situados na interface entre filosofia e linguagem, defendem a tese de que a comunicação está no centro da condição humana, deixando, assim, de ser entendida como o meio pelo qual pensamentos, sentimentos e ideias são transmitidos, para consistir no que os torna possíveis (MuMBy, 2010, p. 26). É na dialética que a comunicação pressupõe que modos de pensar diferentes são confrontados, experiências múltiplas são evocadas, possibilitando ao indivíduo modificar os contornos de sua subjetividade, antes tomados como fixos, definitivos e impermeáveis. Aí reside a relação da comunicação com a humanização, na consideração do outro e no que seu horizonte de expectativas pode nos revelar.

Em Pode o subalterno falar?, Gayatri Spivak (2010, p. 48), indiretamente, toca nessa questão na medida em que problematiza o fato de uma explicação e uma narrativa da realidade, oriunda da perspectiva dominante, terem sido estabelecidas como normativas. Nesse processo, o ponto de vista da mulher, sobretudo o da subalterna, foi ignorado. Isso porque só mediante as conquistas do feminismo, por volta de meados do século XX, foi permitido à mulher falar; ainda assim, a mulher de países periféricos e de classes, etnias, sexualidades marginalizadas, permaneceram silenciadas. No Brasil, um desdobramento dessa constatação é o conceito de escrevivência de Conceição Evaristo (2007), pensado para descrever uma das mais incisivas vias de resistência feminina nos contextos escravagistas e imperialistas. Entrelaçando história, memória e experiência, ele evoca a capacidade de a escritura fazer emergir maneiras outras de existir: "talvez, estas mulheres (como eu) tenham percebido que se o ato de ler oferece a apreensão do mundo, o de escrever ultrapassa os limites de uma percepção de vida. (...) escrever adquire um sentido de insubordinação" (EvARISTO, 2007, p. 20-21).

A prática da escrita, nesse sentido, somada a de outros deslocamentos que as personagens de romances brasileiros contemporâneos, referidos acima, empreendem ao longo de suas trajetórias, não sem muito empenho, sintetizam uma reviravolta em relação ao modo como a cultura dominante tem subalternizado as 
mulheres, nos termos descritos por Spivak (2010). No caso de Breta, a narradora que simbolicamente está nos bastidores de toda a história narrada em $A$ república dos sonhos, embora narre efetivamente apenas 8 dentre os 36 capítulos que compõem o romance, o fato de ser ela a incumbida pelo patriarca da família de contar toda a saga familiar assume grande significação do ponto de vista do abalo que promove nas ideias de base que sustentaram o silenciamento histórico da mulher, aqui representado como definitivamente superado. $\mathrm{O}$ fragmento que segue dá a medida desse gesto:

O avô Xan esforçou-se em reviver as histórias soterradas da Galícia. Enquanto Eulália, Venâncio e eu chegamos ao Brasil com o intuito de misturar as histórias de Xan com as que já existiam aqui. Mas não fomos capazes. Todos nós capitulamos. Conseguimos fazer apenas um episódio desse livro. Agora, só nos resta você. A você caberá escrever o livro inteiro, a que preço seja. Ainda que deva mergulhar a mão no fundo do coração, para arrancar a vida dali. Um livro que, ao falar de Madruga e sua história, igualmente fale de você, de sua língua, do áspero e desolado litoral brasileiro, das entranhas dessas terras que vão do Amazonas ao Rio Grande. Eu viverei no livro que você escrever, Breta. Não receie nos ferir ou mesmo nos matar. É sempre preciso matar e ferir quando se conta uma história. Só assim, Breta, você restaurará a nossa memória, e a manterá viva. E isto enquanto houver a sua língua amada portuguesa (PIÑNN, 1984, p. 760).

Trata-se de um gesto que ganha foros de revisão de valores. Se considerarmos que o romance que temos nas mãos, ao consistir na narrativa da saga familiar de Madruga, focaliza, consequentemente, cinco gerações de mulheres, sendo que quatro delas são afetadas pelo silenciamento historicamente imposto à mulher pela ideologia patriarcal até então dominante, somos levados a tomá-lo como um marco simbólico que fixa o momento mesmo em que a mulher conquista o direito de falar/narrar. E, desse modo, usufruir da plenitude de sua humanidade. $\mathrm{O}$ fragmento acima, embora pareça tratar-se do discurso direto do protagonista, consiste, na verdade, em uma projeção da própria Breta, estando o avô próximo da morte, enquanto ela, já de posse de toda a história, equacionava seu entendimento acerca do projeto da obra que se preparava para escrever: caberia a ela, em sua missão de escritora, escrever a história inteira, ainda que tivesse que ferir a memória do avô, desnudando seus desmandos, seu autoritarismo, sua perspectiva patriarcal e de direita.

Designada pelo próprio Madruga a preservar a memória familiar, a personagemescritora fora ambientada no Brasil dos anos 1960-80, momento histórico marcado por significativas revoluções culturais, que, de certa forma, facilitaram-lhe a desestruturação dos alicerces patriarcais sobre o qual a família fora assentada. Ela representa, no universo romanesco, a mulher que encontrou, através do pensamento feminista reinante em seu tempo, condições para escapar da dependência e da submissão milenar de seu sexo. Trata-se de estar em conjunção com uma liberdade que não fora, sequer, sonhada pela geração de sua avó Eulália. E se a geração 
de sua mãe ousou fazê-lo, fê-lo como pioneira que era da transgressão. Como tal, teve de se submeter, como no caso da própria Esperança, à exclusão da sociedade.

A trajetória de Breta, portanto, examinada em relação às trajetórias de Eulália e Esperança, surge em A república dos sonhos como uma etapa fundamental do ciclo que descreve o processo de emancipação da mulher. Segundo esta linha evolutiva, pode-se ler o modo de construção deste trio de personagens femininas como sendo capaz de historicizar a condição social da mulher, incorporando-lhe mudanças e aceitando-lhe a transitoriedade, sem perder de vista as condições concretas que a acompanham. De modo que é a conquista do direito de narrar o ponto de chegada do percurso que a personagem perfaz, salientando em cada gesto o status da independência e da subjetificação que ostenta. Prenhe de um prazer visceral em se proclamar livre, em uma espécie de vingança à subjugação histórica da mulher - "Não tenho compromissos com ninguém. Só com minhas ideias, disse enfática, senhora de si” (PIÑON, 1984, p. 266) -, ela empreende ao longo de sua trajetória deslocamentos de ordem diversa em relação aos parâmetros impostos pelo pensamento patriarcal, então, vigente, seja quando se proclama livre no âmbito de sua vida amorosa e sexual, recusando os códigos matrimoniais, seja quando faz escolhas políticas contraideológicas, seja quando expõe tudo isso no âmbito familiar, sem o receio da interdição.

Ao trazer a história da evolução da condição social da mulher para o universo da ficção, Piñon o faz inscrevendo-a na linhagem do pensamento feminista empenhada na desconstrução de gênero ou na subversão de modelos culturais cristalizados que oprimem e excluem sujeitos. Para Judith Butler (2001), uma das principais perspectivas feministas representantes dessa linha de pensamento, o gênero implica assumir um modo de viver o corpo no mundo; trata-se de um ato de interpretação da realidade cultural sancionadora. Tomando como ponto de partida a desconstrução de Derrida e a psicanálise de Freud e Lacan, ela rompe com o sistema sexo-gênero, eliminando seu marco binário, apoiada na tese de que os corpos não se adaptam às normas segundo as quais sua materialização é imposta. O gênero é concebido face ao construto cultural imposto sobre a superfície da matéria, ou seja, o corpo, o sexo; o gênero absorve e desloca o sexo, cuja ideia é produzida, e também desestabilizada, no curso da reiteração das normas sociais. Nesse sentido, a opressão da mulher e a inferioridade a ela atribuída não são inerentes à sua natureza, mas construídas, paulatinamente, ao longo da cultura; não sendo naturais, e considerando o empenho da própria mulher em desestabilizá-las, há que se substituírem as abordagens e/ou representações de seu processo histórico alicerçadas na permanência, por outras que focalizem conjunturas provisórias e concretas, transcendendo definições estáticas e desconstruindo categorias abstratas.

É o que ocorre quando da representação da narradora-protagonista de A república dos sonhos (1984). O direito de falar/narrar encontra-se no vértice da sua maneira de vivenciar o corpo que, em tempos de feminismos, não mais pretende suportar o rótulo de subalterno, disciplinado, imobilizado, entre outros da mesma li- 
nhagem, conforme reza a tipologia de Xavier no seu Que corpo é esse? (2007). Reverberando a vocação da sua condição humana, ela performa o gênero feminino no qual se inscreve - com suas particularidades e diferenças - para além de padrões prescritivos e hierarquizados de orientação patriarcal. Seu corpo liberado, delibera acerca do próprio itinerário, corporificando, no ato mesmo da fala/narrativa, sua capacidade de agência, de atualizar maneiras de pensar, sentir e vivenciar a realidade, fazendo jus à plenitude da sua humanidade.

\section{Referências}

Bhabha, Homi. The right to narrate. Harvard Design Magazine, Cambridge, Summer, 2014. (on-line). Disponível em: http://www.harvarddesignmagazine.org/ issues/38. Acesso em: 5 jul. 2018.

Butler, Judith. Corpos que pesam: sobre os limites discursivos do "sexo". Tradução de Tomaz Tadeu da Silva. In: Louro, Guaciara Louro. (org.). O corpo educado: pedagogias da sexualidade. Belo Horizonte: Autêntica, 2001.

ButLer, Judith. Problemas de gênero: feminismo e subversão da identidade. Rio de Janeiro: Civilização Brasileira, 2003.

Evaristo, Conceição. Da grafia-desenho de minha mãe, um dos lugares de nascimento de minha escrita. In: Alexandre, Marcos Antonio (org.). Representações performáticas brasileiras: teorias, práticas e suas interfaces. Belo Horizonte: Mazza, 2007 .

Hall, Stuart. A identidade cultural na pós-modernidade. Tradução de Thomas Tadeu da Silva e Guacira Lopes Louro. 11. ed. Rio de Janeiro: DP\&A, 2006.

Mumby, Dennis K. Reflexões críticas sobre comunicação e humanização nas organizações. In: Kunsch, Margarida Maria Krohling. A comunicação como fator de humanização das organizações. São Caetano do Sul, SP: Difusão, 2010.

Piñon, Nelida. A república dos sonhos. Rio de Janeiro: Francisco Alves, 1984.

Pollak, Michael. Memória e identidade social. Revista Estudos Históricos. Rio de Janeiro, v. 5, n. 10, p. 200-215, jul. 1992. Disponível em: http://bibliotecadigital.fgv. br/ojs/index.php/reh/article/view/1941/108. Acesso em: 5 jul. 2018.

Schmidt, Rita Terezinha. A transgressão da margem e o destino de Celeste. In: Reis, Lívia de Freitas; Vianna, Lúcia Helena; Porto, Maria Bernadette (orgs.). Mulher e Literatura: VII Seminário Nacional, volume 2. Niterói: EdUFF, Sette Letras, 1999. p. 672-682.

SpIvak, Gayatri Chakravorty. Pode o subalterno falar? Belo Horizonte: Editora da UFMG, 2010.

XAVier, Elódia. Que corpo é esse?: o corpo no imaginário feminino. Florianópolis: Mulheres, 2007. 
Zolın, Lúcia Osana. Desconstruindo a opressão: a imagem feminina em "A república dos sonhos”, de Nélida Piñon. Maringá: Eduem, 2003.

Zolın, Lúcia Osana. Estratégias de subjetificação na ficção contemporânea de mulheres: exílio, migração, errância e outros deslocamentos. Acta Scientiarum: Language and Culture. Maringá, PR, v. 40, n. 2, p. 1-17, jul./dez. 2018a.

Zolın, Lúcia Osana. Mulheres que escrevem e se (re)escrevem na ficção recente de autoria feminina. In: SAlgado, Maria Teresa et al. (orgs.) Escritas do corpo feminino: perspectivas, debates e testemunhos. Rio de Janeiro: Oficina Raquel, 2018b.

Recebido em 13 de novembro de 2019.

Aprovado em 2 de março de 2020.

\section{Resumo/Abstract/Resumen}

Sob o primado da palavra: o universo feminino/feminista das mulheres d'A República dos sonhos, de Nélida Piñon

\section{Lúcia Osana Zolin}

Trata-se de uma leitura de A república dos sonhos, de Nélida Piñon, alicerçada na teoria crítica feminista, por meio da qual pretendo evidenciar o modo de representação de personagens femininas que compõem o romance, atrelado à perspectiva sociocultural da escritora e ao pensamento feminista. Nessas reflexões, saliento que o processo de subjetificação galgado pelo conjunto das mulheres da obra, e sintetizado na figura de Breta, passa pela conquista do direito de narrar/falar, nos termos de Gayatri Spivak (2010) e de Homi Bhabha (2014). A ancestral subalternidade feminina, nesse sentido, é superada à medida que a narradora-protagonista vai se constituindo como sujeito, no movimento mesmo em que se investe da capacidade enunciativa e toma a palavra.

Palavras-chave: Nélida Piñon, A república dos sonhos, personagem feminina, narradora.

The primacy of words: the female/feminist universe of the female characters in A república dos sonhos by Nélida Piñon

\section{Lúcia Osana Zolin}

This is an interpretation of Nélida Piñon's novel The Republic of Dreams based on the feminist critical theory, through which I intend to evidence the way female characters are represented in the novel, connected to the writer's sociocultural perspective regarding feminist thinking. As a result of my thoughts, I wish to highlight that the subjectification process which the female characters undergo, which is synthetized by Breta, comprises the attainment of the 
right to narrate/speak, in the words of Gayatri Spivak (2010) and Homi Bhabha (2014). Ancestral female subalternity, in this sense, is overcome insofar as the protagonist-narrator achieves the status of 'subject' while embodying enunciative competence, thus, taking the floor.

Keywords: A república dos sonhos, female characters, female narrator.

Bajo la primacía de la palabra: el universo femenino/feminista de las mujeres en A República dos sonhos, de Nélida Piñon

\section{Lúcia Osana Zolin}

Este artículo trata sobre una lectura de A república dos sonhos, de Nélida Piñon, cimentada en la teoría crítica feminista, a través de la cual pretendo resaltar la forma de la representación de los personajes femeninos que componen la novela, además de la perspectiva sociocultural de la escritora sobre el pensamiento feminista. A lo largo de estas reflexiones, destaco que el proceso de subjetivización alcanzado por el grupo de mujeres en la obra, y sintetizado en la figura de Breta, pasa por la conquista del derecho de narrar/hablar, en los términos de de Gayatri Spivak (2010) y de Homi Bhabha (2014). La ancestral subalternidad femenina, en este sentido, es superada en la medida en que la narradora y protagonista se va constituyendo como sujeto, en el propio movimiento en que se inviste de capacidad enunciativa y toma la palabra.

Palabras clave: Nélida Piñon, A república dos sonhos, personaje femenino, narradora. 